\title{
Application of electroosmosis and monitoring for the management of geotechnical processes in underground construction
}

\begin{abstract}
A new concept for the selection of rational construction and engineering parameters for the building of large deep-set edifices is set out for an environment where the requirements on preservation of historical sites and rational usage of land in big cities and growing more taxing. Based on the proposed geotechnical model, and the assessment of the results of quantitative modelling, research and experiments, a number of techniques have been developed intended to optimise the technological modes of construction under adverse urban conditions involving hard-to-handel soils and constrained urban ambience.
\end{abstract}

Volume 2 Issue 4 - 2018

\author{
Perminov NA \\ Emperor Alexander I State Transport University, St. Petersburg, \\ Russia \\ Correspondence: Perminov NA, Emperor Alexander I State \\ Transport University, St. Petersburg, Russia Email \\ perminov-n@mail.ru
}

Received: August 06,2018 | Published: August 16, 2018

\section{Application of geotechnics and monitoring in solving problems of construction of unique underground structures in difficult conditions}

Today the problem of working out the complex measures providing high quality building turns out to be very actual. It could be explained by growing demands towards ecology, earth resources and environment protection against negative technogenic influence Geo monitoring systems rank among such measures.

The experience in design and construction of sewage treatment systems and constructions had proved such systems necessity. It is wellknown that for such purposes main pump stations are usually build with dipping method. Today St. Petersburg and many large cities all over the world are facing the problem of metro construction connected with the lack of free territory. In connection with it we propose to build junction metro stations of St-Petersburg metro in large-sized dipping wells (Figure 1).

We propose to use a construction with 66.0meters in diameter and 70.0 meters high for that purpose. It will allow to organise the junction terminal in the lower part of the well. The upper part could be used for a 7-stored underground garage for 850 cars. Due to that we would save 15000 square meters of the city territory. Usually the constructions of the described type are deepen into the ground for 70meters. Their cross section ranges from 2000 to 3000 sq. meters. So the contacting area between their lateral surface and the ground is from 150 to 200 thousands of sq. meters. When being used these constructions cross several (above 5) aquifer levels and greatly influence upon the surrounding buildings and geologic environment. The type and the after-effect of such influence differ from time to time. On one hand they are determined by the engineering and geological conditions of the construction site. On the other hand - by the designing and technological peculiarities of the deepen constrution and it's building. Hence there is a problem how to exclude or minimise the above mentioned negative after-effect. To be settled this problem needs the systematic approach towards joint solving of geotechnical and engineering problems.

Today we are undertaking the works upon geo- monitoring system creation. This system is being implemented step by step in Northern and Southern sewage systems construction. The geo-monitoring system structure is based on the following subsystems. ${ }^{1-4}$

a. The program system calculating and forecasting the changes in technical and geological conditions and strained and deformed state (SDS) of geological block under different building modes for dipping constructions;

b. The technical tools subsystem for instrument observations and monitoring of "construction - geo block" system elements;

c. Informational and measuring subsystem for gathering, processing storing and identification of observation and monitoring data;

d. The system of geo-technological methods for determinated operation upon ground block and construction;

e. Automation and optimum control subsystem for geotechnological and other processes.

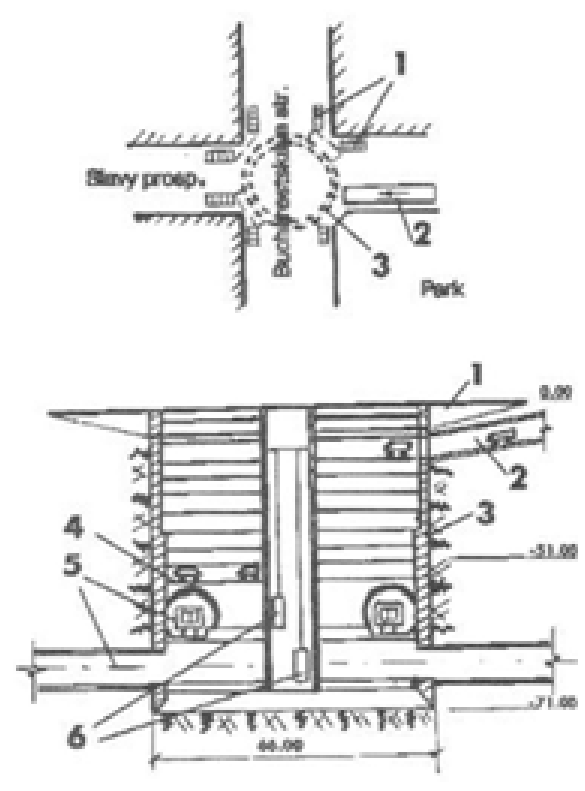

Figure I Multifunctional deep-set junction terminal (Location), (Junction terminal plan), I, Pedestrian cross; 2 , Underground garage entrance; 3, Deepset edifice; 4, Underground garage; 5, Junction terminal stations; 6, Lift shaft. 
We have large experience in implementing of different methods providing reliability and quality in deeping constructions building. Our experience shows that geo-monitoring system should be adapted to control the processes in semi-continuous mode and in real time. Some research institutes had used strained and deformed state control system for deeping wells construction. The results shoe that every deviation from the project is registered by the control instruments. However it's a great problem to use this data for determinated process control. It is explained by the fact that it takes much time from the moment of getting the initial data to the moment of it's analysis and issuing the recommendations for some technological steps. It is connected with the long period of time needed for data processing. Unfortunately the structural and geo - engineering conditions also change meanwhile.

Our investigations gad shown that it's possible to provide the reliability and uniformity for edifices deeping process. It could be achieved by creating the semi-continuous interaction system for the three- dimensional ( $\mathrm{dX}, \mathrm{dY} . \mathrm{d} \mathrm{Z}$ ) and time (dt) process variables. ${ }^{5,6}$

We have taken out some estimate-theoretical and research works. As a result we have worked out and tested the complex system providing the geo- technical support for deep-set edifices deeping process. These edifices were from 50 to 70 meters in diameter. They had been implemented in waste treatment facilities construction in St. Petersburg. The mentioned above system comprises three following complexes: measuring-control complex; signal estimation and transmission for process control purposes; immediate feed-back complex. The measuring-control complex provides monitoring for the SDS orientation of edifice shell and ground massive. It includes spatial orientation instruments (laser range finder, volumetric reflectors, bank angle detectors). Besides, it includes the instruments estimating ground resistance along the lateral surface of the edifice, ground lateral pressure, ground pressure under the edifice knife banquet, reinforcement stress, concrete distortion..$^{7-10}$

SDS control system provides monitoring of the following variables characteristic for the "deep-set edifice - geomass" behaviour:

i. Ground SDS, that is estimated by the results of contact pressure, pore pressure and ground shift detection ;

ii. Edifice material SDS concrete and reinforcement including;

iii. Deep set edifice swaging and banks.

iv. Ground subsidence (on the adjacent territory).

Initial transformers are installed in $6-8$ section points in edifice shell perimeter from 5 th to 10 th layers. E.g.: There were 86 pressure, friction temperature and other transformers installed in the deep-set edifice with 49,6 meters diameter. Strain sensors, steam pressure detectors, string hydraulic sensors and rigid string hydraulic sensors were used for contact pressure measuring.

\section{The results of reinforcement strain and distortion}

detection were used to estimate the Edifice shell SDS. String detectors and strain sensors that were stacked to the reinforce were used for that purpose. Edifice bank was detected by the bank sensors. Those sensors are based on double string gauging transformers (measuring accuracy didn't exceed $10 \mathrm{sec}$ ). Semi continuous system for detectors' indication registration includes the following instruments: portable digital lime setter, 20 channel electronic communicator, controller (stand alone interface module) Kl-20; controller remote control unit; power supply unit; wiring cables (controller, controller communicator, power supply - controller; PC controller, power supply - battery, communicator, periodic tolling controller, communicator sensors).

We have proposed new geo-technical methods for unique largescale edifices. These methods are based on geo mass SDS controlling not only in the basement but also in it's lateral surface.

Essentially the described methods and their realisation technique are as follows:

a. Geo mass natural SDS estimation is fulfilled at the designing stage through numeral calculations (e.g.: Finite elements method).

b. Geo mass SDS and well orientation forecast is worked out on base of the above mentioned calculations. Besides we can build a model of edifice vertical angular deviation.

c. We can forecast the location of deeping marks with the damage emergency. On base of such forecasts we can select the most acceptable geo- technical methods for geomass SDS measuring not only at the edifice base but also in the lateral surface. Besides we can select the methods to change the conditions for their contact interaction.

d. We can make the techno-echonomical estimation and select the optimum method to provide deeping process reliability and acceleration.

We had fulfilled several cycle calculations with Finite elements method for the ground conditions typical for St. Petersburg (Quaternary sediments 26-35meters deep, underlayed by hard Cambrian clays). As a result of computing experiment we had calculated the admissible deviation ' $\mathrm{dh}$ ' from the vertical axes and non-deforming fits 'di' values. We have come to a conclusion that tixothropic jacket is the best possible solution in this case. It results in friction strength decrease on the marks from 16 to 47 meters. Hovering stability is achieved through electroosmosis up to 16 meters height and with ' $\mathrm{di}$ ' $<0.015$. We propose dedicated method for geomass preparation to correct the bank for ' $h$ ' and di high values. Besides, what we propose is the discharge well design in knife and lateral surface areas.

The described above results of using geomonitoring system for large diameter deep-set edifices construction could be successfully implemented for large scale basements construction. Besides it might be used for deep-set edifices construction in hard and complicated ground conditions. Also these methods could be used for developing and reconstruction of existing underground territories in large cities.

\section{Structural and geo-technological model for large scale deep-set edifices construction in under city building system conditions}

To save city building environment we have worked out the structural geo-technological model of large scale edifice construction. This model is created considering the characteristic features of interaction between structural and technological processes on one side and engineering and geological processes on the other. Being the monitoring object the deep-set edifice is represented as a geotechnical system (GTS) - that is the interconnected and interlined assembly of technical object (TO) (the deep-set construction itself) 
and of geological object (GO) (the ground) Figure 2..11,12 Technical object is a steric one with the concentrated infiuence and distributed structural and technological parameters. Geologic object is an assembly of city building and geomechanical elements that might be combined corresponding to geological environment model.

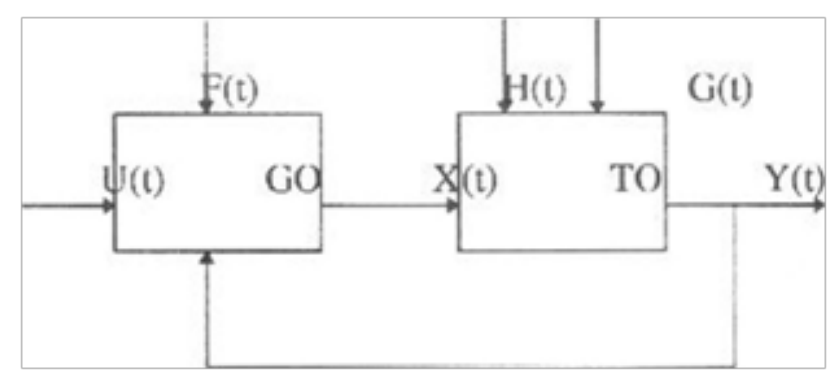

Figure 2

GTS is influenced by a great number of factors that could be devided into three following groups:

a. Construction elements mass $(\mathrm{G})$;

b. Geological environment reaction (X);

c. External (artificial and natural) disturbance $(\mathrm{H})$.

Each vector: $\mathrm{G}, \mathrm{H}, \mathrm{X}$, consists of numerous factors. The greater part of those factors is unknown. To determine them multidimensional distribution law for probability distribution should be defined. ${ }^{13}$ Please find bellow the equation that describes the process of deep-set edifice construction and functioning. This equation describes it in a simplified mode according to the common principals.

$$
\begin{aligned}
& a(H, G, X, t) d \ddot{I} / d t=R-R_{e}(x) \\
& R=R_{e}+R_{p}
\end{aligned}
$$

Where II is a reducted factor of target product output (by the specific volume of deep-set edifice internal volume),

$\mathrm{R}, \mathrm{R}_{\mathrm{e}}, \mathrm{R}_{\mathrm{p}}$ - reducted expenditures (reducted costs, power and labour expenditures);

\section{$\mathrm{t}$ - time of functioning.}

The task for optimum GTS monitoring could be formulated in the following way: one is to find the control rules $\mathrm{U}(\mathrm{t})$ for GTS taking into consideration a set of regulations. These regulations transfer technological and geological objects to the monitoring mode. Optimum function should have an extreme and is expressed with the following equation. ${ }^{14}$

$$
F n=\int_{\mathrm{t}_{0}}^{\mathrm{tn}_{\mathrm{n}}} P(Y, U, H, G, t) d t \max
$$

Where $\mathrm{P}$ is continuous function of output variable $\mathrm{Y}$ and of controlling influences $\mathrm{H}, \mathrm{G}, \mathrm{U}$

Optimum criteria for the whole period of GTS development and functioning (e.g.: deep-set well construction) is represented as a sum optimum criteria elements on each construction stage (installation and deeping).

$$
F=\sum F_{n}
$$

Optimum GTS control is reduced to the step by stem To and GO variables control. The control is fulfilled according to the algorithm of optimum way of aim achievement. So our aim is to settle the problem of deeping the well shell under the optimal geo-technological conditions in the preset time or with the minimum influence upon city building environment.

\section{Geo-technical research and manufacturing results}

Geo-technical research works include large scale laboratory experiments, quantitative modelling by Finite elements method and site testing. To simulate the conditions of deeping by Finite elements method we had used incremental ground model, based on generalised Gook principle. The relation between strain and deformation increments was computed separately for stress tensor deviation and spherical components. ${ }^{15}$

$$
\begin{aligned}
& d S_{i j}=2 G^{T} * d e_{i j} \\
& d \sigma_{\tilde{n} \tilde{\delta}}=3 K^{T} * d \varepsilon_{c p}
\end{aligned}
$$

Where $\mathrm{dS}_{\mathrm{ij}}$ and $\mathrm{de}_{\mathrm{ij}}$ - stress and deformations tensors deviation components increments respectively;

$\mathrm{d} \sigma_{\mathrm{cp}}$ and $\mathrm{d} \varepsilon_{\mathrm{cp}}$ - average stress and deformation values increments;

$\mathrm{G}^{\mathrm{T}}$ and $\mathrm{K}^{\mathrm{T}}$ - tangent modules of shape and object deformation.

First in laboratory and then on the site we have carried out the investigation to find out the tixothropic solution features influence upon the large scale deep-set edifices deeping process. The plan of monitoring instruments location is shown in Figure 3. The results of friction and pressure strength detection are shown in Figure 4. Engineering and geological conditions of the construction site are typical for St. Petersburg city building environment. It means that the territory is formed by the grounds of Quaternary sediments 26 35 meters deep, underlayed by semi hard and hard Cambrian clays up to the 71.0 meter depth.

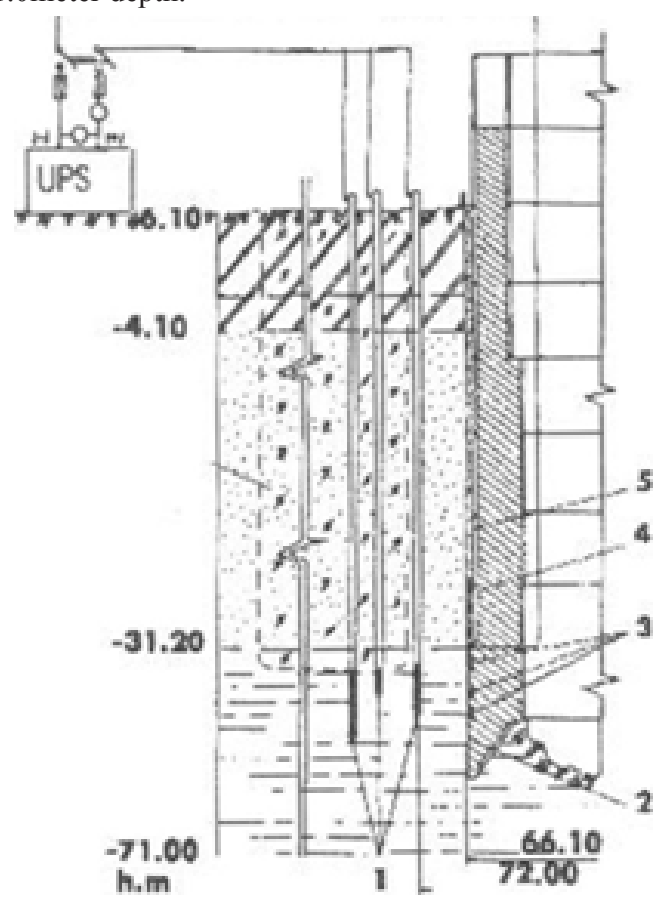

Figure 3 Instruments location plan on the deep- set well: I,2, Pressure and friction sensors; 3 , Reinforcement dynamometer; 4 , Wiring cables; 5 , Control station. 
The well for Northern waste treatment facilities with 66.1 meter diameter is designed as a monolith unite. We had included a tixothropic jacket into construction to provide the deeping process reliability. Deeping process quantitative modelling for large scale wells in the inclined layers of Cambrian clays had shown the necessity of control system for deeping process. The system included electroosmosis plant and instrumental control net. ${ }^{1,4,16}$ Electroosmosis plant comprised the electrode bell 10.5 meters high mounted on the knife external surface and 45 tube electrodes. The electrodes were located along three concentric circles. The distance from the well external ring was 3,6 and 7 meters. They were dipped to the $41.0-43.0$ meters height. The rectifiers were used as power supply units for DC voltage. They had provided $74 \mathrm{~V}$ and 3300A (Figure 5). The controlled deeping process was conducted in the following way. First the ground was electrically treated with for 1.5-3.0 hours (voltage gradient was $0.2 \mathrm{~V}$ per sm, current density was about $2 \mathrm{~A} / \mathrm{sq} \mathrm{m}$. Then the well was gradually deepen. Previously the well had been motionless for several Jays (Figure 6). Preliminary electrical treatment allowed to increase the deeping rate 2.5-3.0times. The deeping rate ranged from 5 to $15 \mathrm{sm}$. per minute, the electrode polarity being changed deepening rate abruptly went down, the bank was corrected and the deeping stopped., ${ }^{3,17}$. For Southern waste treatment facilities the deeping well was 51.0 meter in

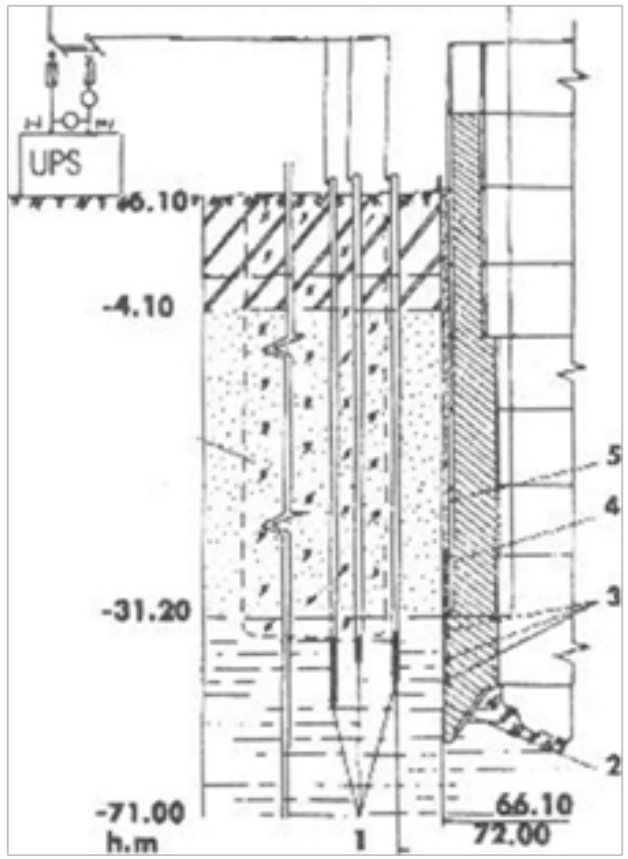

Figure 5 Scheme for electroosmosis edifice deeping, I,2, Tube electrodes and electrode belt; 3 , Control instruments; 4 , Clay solution.

\section{Acknowledgements}

None.

\section{Conflict of interest}

The author declares there is no conflict of interest.

\section{References}

1. Tikhomolova KP. Electroosmosis. Chemistry. 1989. 248 p.

2. Ivliev EA. Soil mechanics and foundation engineering. Grounds Foundations and mechanics of soils. 2015;6:14-18. diameter. The deeping height was 49.0meters. Anodes and cathodes were located on the knife part of the construction in interchange order. The clay solution had the access to the electrodes. As a result we had achieved deeping acceleration, bank correction and eliminating of negative influence upon city building environment.

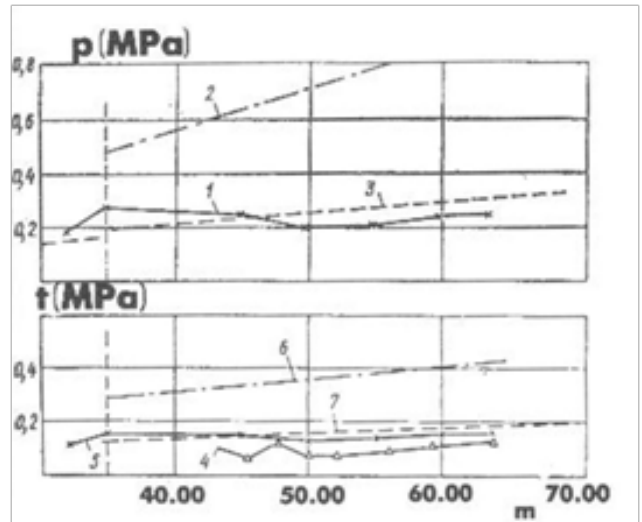

Figure 4 Pressure and friction measurements during the deeping process, I,4,5, Experimental data; 3,6,7, Computering values for ground pressure and friction.

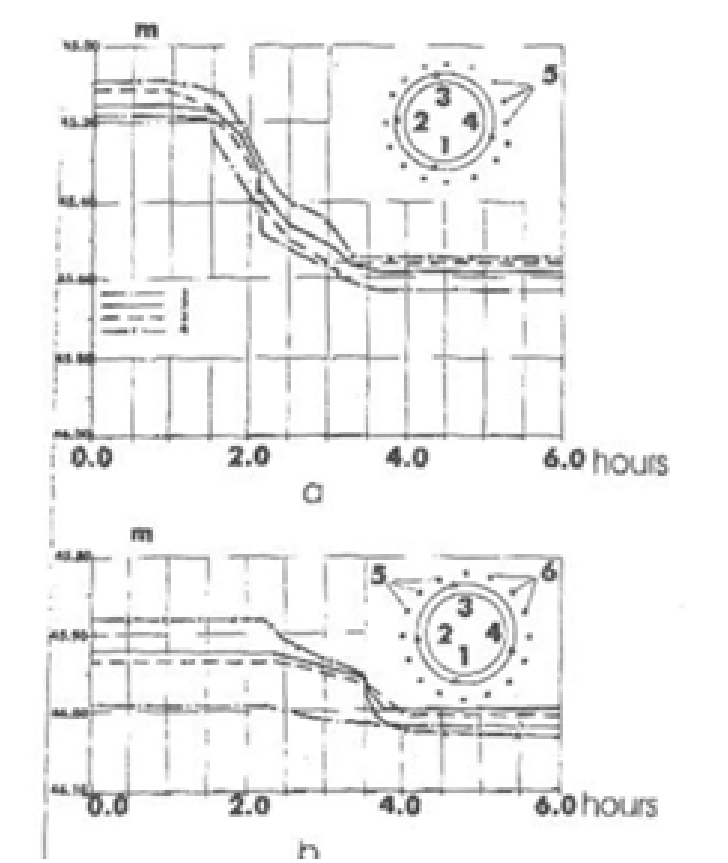

Figure 6 Electroosmosis deeping diagram phragments; a, Even deeping; b, Bank correction; I,2,3,4, Fixed points; 5,6, Electrodes (catodes and anodes).

3. The Main Directions of Providing Reliability of Exploitation of Railway Engineering Structures at the Contemporary Technical and Technological Level. 2013.

4. Perminov NA. Geotechnical Aspect of Safety Assurance for Long-Used Engineering Infrastructure Facilities in Large Cities in Complicated Ground Conditions. Geotechnics of Roads and Railways. 2014;1195-1201.

5. Perminov NA. Complete geotechnical and monitoring services for the construction of the underground structure in a megapolis. Proceedings of the International Geotechnical Conference. Almaty. 2004;361-366.

6. Bridge and culvert limit pase on big earth and rock project. Highway and Heavy Constr. 1986;129(7):40-41. 
7. Hebden RH. Segmental precast culverts for the coquihalla Fraway. Concr Transp Detroit. 1986;769-795.

8. The Technical Conditions for Conducting Planned and Preventive Repairs of Railway Engineering Structures in Russia for the Central Track Service 622. 2008.

9. Pinto A. Tomasio R. Pita X. et al. Gutter soil mixing solutions in Portugal on hard soil and weak rocks. Proceeding of the 15th European conference on soil mechanics and geotechnical engineering. Athina. 2011;2:1037-1042.

10. Serebryakov DV. Of the study on vibrational process of soil roadbed on the sections of the pairing of railway track with bridges. Proceedings of international scientific conference Transportation system infrastructure problems. Saint-Petersburg Russia. 2015;240:52-55.

11. Kolos A, Konon A. Estimation of railway ballast and subballast bearing capacity in terms of $300 \mathrm{kN}$ axle load train operation. In: Askar Zhussupbekov, editor. Challenges and Innovations in Geotechnics. Proc intern conf Astana, Rotterdam: Balkema. 2016.

12. Emst, Sohn GmbH. Recommendation of Design and Analysis of Earth Structures using Geosynthetic Reinforcements-EBGEO. Gennan Geotechnical Society. 2011.
13. Pankova GA. Klementiev MN. The experience of exploitation of sewage tunnels in St. Petersburg. Water supply and sanitary equipment. 2015;3:55-61.

14. Vasiliev VM. Pankova GA. Stolbikhin Yu V. Destruction of sewage tunnel and above structures due to the impact of microbiological corrosion. Water supply and sanitary equipment. 2013;9:55-61.

15. Wells T. Melchers RE. Modelling concrete deterioration in sewers using theory and field observations. Cement and Concrete Research. 2015;77:82-96.

16. Hobbs DW. Expansion and cracking attributed to delayed ettringite formation. Proceedings of a Technical Session Ettringite, ACI Seattle Washington, SP-177. 1999;151-181.

17. Grammond NY. Quantitative X-ray diffraction analysis of ettringite thaumasite and gypsum in concrete and mortars. Cement and Concrete Research. 1985;15(3):431-441. 